\title{
Fasting plasma triacylglycerol concentrations predict adverse changes in lipoprotein metabolism after a normal meal
}

\author{
BY JENNIFER L. POTTS ${ }^{1}$, SANDY M. HUMPHREYS ${ }^{1}$, SIMON W. COPPACK $^{1 *}$, \\ RACHEL M. FISHER ${ }^{1}$, GEOFFREY F. GIBBONS ${ }^{2}$ AND KEITH N. FRAYN ${ }^{1} \dagger$ \\ ${ }^{1}$ Oxford Lipid Metabolism Group, Sheikh Rashid Laboratory, Radcliffe Infirmary, \\ Oxford $O X 26 \mathrm{HE}$ \\ ${ }^{2}$ Metabolic Research Laboratory, Nuffield Department of Clinical Medicine, Radcliffe Infirmary, \\ Oxford $O X 26 H E$
}

(Received 2 August 1993 - Revised 8 November 1993 - Accepted 9 November 1993)

\begin{abstract}
The changes in lipoprotein metabolism which follow the ingestion of a large fat load have been well described. The hypothesis was tested that similar changes in lipoprotein metabolism would occur after a relatively normal meal. Plasma and lipoprotein triacylglycerol, cholesterol and apolipoprotein concentrations were determined in twenty subjects (ten female) given a mixed meal containing approximately one-third of the daily intake of major nutrients in the typical Western diet. Fasting plasma triacylglycerol concentrations (range $0.38-2.70 \mathrm{~mm} / \mathrm{l}$ ) and the postprandial rise in plasma triacylglycerol varied considerably between subjects and were significantly associated $(P<0.01)$. The rise in plasma triacylglycerol corresponded to marked increases in the triacylglycerol concentration of the triacylglycerol-rich lipoproteins (TRL; chylomicrons and very-low-density lipoproteins). TRL cholesterol also increased after the meal. An increase in high-density-lipoprotein (HDL)-triacylglycerol following the meal was accompanied by a decrease in HDL-cholesterol concentration, presumably due to the action of the cholesteryl-ester transfer protein. The increases in HDL-triacylglycerol and in TRLcholesterol were correlated with the postprandial rise in triacylglycerol in the TRL $(P<0.01)$. We conclude that potentially adverse changes occur in both triacylglycerol-rich and high-density lipoproteins following a typical mixed meal, as they do after large fat loads. The changes are exaggerated in those subjects with greater fasting plasma triacylglycerol concentrations.
\end{abstract}

Postprandial metabolism: Triacylglycerol: Chylomicrons: Very-low-density lipoprotein

Although epidemiological studies of risk factors for coronary heart disease usually involve measurement of lipoprotein levels after overnight fast, there is considerable evidence that the dynamic processes occurring in the postprandial state are particularly important for atherogenesis. After a large fat load the elevation in plasma triacylglycerol (TAG) concentration is accompanied by alterations in all lipoprotein classes, including highdensity lipoprotein (HDL) (Havel et al. 1973; Redgrave \& Carlson, 1979; Tall et al. 1982; Groot \& Scheek, 1984). There is considerable variation amongst individuals in the magnitude and duration of the plasma TAG response to a fat load. Impaired postprandial clearance of circulating TAG is associated with low (fasting) HDL-cholesterol concentrations, and both hypertriacylglycerolaemia and low HDL-cholesterol are associated with increased risk of coronary heart disease (Simpson et al. 1990; Miesenböck \& Patsch, 1992).

The changes occurring in the postprandial period after large fat loads have been

* Present address: Department of Medicine, University College London Medical School, Archway Wing, Whittington Hospital, Highgate Hill, London N19 3UA.

$\dagger$ For reprints. 
described in detail in normal (Redgrave \& Carlson, 1979; Cohn et al. 1988, 1989), hyperlipidaemic (Redgrave \& Carlson, 1979; Lewis et al. 1991; Karpe et al. 1993) and obese (Lewis et al. 1990) subjects. However, there has been little study of the responses to ingestion of more typical amounts of fat given as part of a mixed meal. Without such studies it is not clear whether the phenomena observed after larger fat loads are relevant to atherogenesis in normal daily life. We have therefore investigated the changes in lipoprotein metabolism occurring after a relatively normal mixed meal, in a group of subjects with widely differing initial TAG concentrations (achieved by selecting people with a range of body mass indices). Our hypothesis was that similar, albeit less marked, changes to those described after large fat loads would occur after a typical meal, and that these would be exaggerated in subjects with elevated initial TAG concentrations.

The studies were performed as part of more detailed studies on adipose tissue metabolism after a mixed meal. Therefore, some of the plasma TAG concentrations, in selected subgroups of the subjects, have been published separately (Coppack et al. 1990, 1992; Potts $e t$ al. 1991).

\section{MATERIALS AND METHODS \\ Subjects and experimental design}

Twenty subjects (ten female) were studied. Their ages ranged from $24-64$ years and body mass index (BMI) values from 19.6-56.2 kg/m $\mathrm{m}^{2}$. They were recruited from hospital staff and other colleagues, and some of the more obese subjects from general medical and diabetic out-patient clinics. Recruitment was made with no knowledge of lipid status. Two of the obese subjects had previously been diagnosed as having non-insulin-dependent diabetes mellitus, but they were well controlled on diet alone and at the time of attendance for these studies had normal plasma glucose concentrations. The overall range of fasting plasma glucose concentrations was $4 \cdot 44-5.78 \mathrm{mmol} / 1$, with a median value of $5 \cdot 04 \mathrm{mmol} / \mathrm{l}$. The studies were approved by the Central Oxford Research Ethics Committee and all subjects gave informed consent. Before the study the subjects fasted for at least $12 \mathrm{~h}$. All studies were carried out in a temperature-controlled room at $23^{\circ}$.

A cannula was inserted either into a vein draining a hand which was warmed in a box at $60-70^{\circ}$ to provide arterialized samples, or into a radial artery. The subject rested for at least $30 \mathrm{~min}$. Three sets of samples were then taken at 20 min intervals to obtain a mean basal value. The subject then consumed a mixed meal, as described in earlier studies (Coppack et al. 1990). The meal had an energy content of $3.1 \mathrm{MJ}$ (740 kcal), of which $47 \%$ came from carbohydrate $(92.5 \mathrm{~g}$, of which $41.7 \mathrm{~g}$ were simple sugars) and $41 \%$ from fat, and was eaten in $20 \mathrm{~min}$. Further samples were taken at $30 \mathrm{~min}$ intervals up to $2 \mathrm{~h}$ and then at hourly intervals until $6 \mathrm{~h}$ after the start of the meal.

\section{Isolation of plasma lipoproteins}

Blood samples were taken into heparinized syringes (Monovette; Sarstedt, Leicester, Leics.). Lipoproteins were separated by ultracentrifugation based on the method of Havel et al. (1955).

Chylomicrons were isolated by layering $2 \mathrm{ml}$ plasma under a solution of density $1.006 \mathrm{~g} / \mathrm{ml}$ followed by ultracentrifugation for $30 \mathrm{~min}$ in a Beckman $50.1 \mathrm{SW}$ rotor (Beckman Instruments (U.K.) Ltd, High Wycombe, Bucks.) at an average of $58450 \mathrm{~g}$. The chylomicrons were obtained by removing the top layer of the tube in a Beckman tube-slicer. Very-low-density lipoprotein (VLDL), low-density lipoprotein (LDL) and HDL were prepared either by sequential flotation or density gradient ultracentrifugation. (In four subjects only chylomicrons and VLDL were isolated.) 
For sequential flotation the chylomicron infranate was transferred to a Beckman $6 \mathrm{ml}$ polyallomer bell-top tube. The tube was then filled with a solution of density $1.006 \mathrm{~g} / \mathrm{ml}$ and centrifuged for $16 \mathrm{~h}$ in a forty-four-place Beckman 50.4 Ti rotor in two concentric rings (inner ring $145000 \mathrm{~g}$ (average), outer ring $172000 \mathrm{~g}$ (average)). The VLDL fraction was isolated by removing the top layer of the tube by slicing. The VLDL infranate $(3.6 \mathrm{ml})$ was then adjusted to a density of $1.063 \mathrm{~g} / \mathrm{ml}$ and was transferred to a bell-top centrifuge tube. The tube was then filled with a solution of density $1.063 \mathrm{~g} / \mathrm{ml}$ and centrifuged for $16 \mathrm{~h}$ as above. The LDL fraction was obtained by removing the top layer of the tube by slicing, the HDL fraction remaining in the infranatant.

For density gradient separation, chylomicrons were isolated as above, and then $2 \mathrm{ml}$ of the infranate was adjusted to a density of $1.21 \mathrm{~g} / \mathrm{ml}$ by addition of $0.653 \mathrm{~g} \mathrm{KBr}$. Of this, $1.5 \mathrm{ml}(1.815 \mathrm{~g})$ were transferred into a bell-top tube and overlayed with the density solution $1.006 \mathrm{~g} / \mathrm{ml}$. Centrifugation was then carried out in a $50.4 \mathrm{Ti}$ rotor for $3 \mathrm{~h}$ (inner ring $227000 \mathrm{~g}$ (average), outer ring $269000 \mathrm{~g}$ (average)). The VLDL fraction was isolated by removing the top layer of the tube by slicing. The LDL fraction, visible in the tube as a yellow band, was then isolated by slicing just above and below the band. The remaining infranate contained the HDL.

In twenty randomly selected pre- and postprandial VLDL and chylomicron samples apolipoproteins B48 and B100 were separated by SDS-polyacrylamide gel electrophoresis. In fasting samples there was a trace of apolipoprotein (apo) B100 in the chylomicron fraction but no apo B48 in the VLDL fraction. In postprandial samples only apo B48 was visible in the chylomicron fraction and apo B100 in the VLDL. Nevertheless, it is accepted that the 'chylomicron' and 'VLDL' fractions isolated by ultracentrifugation are not necessarily completely representative of intestinal and hepatic particles respectively, and for most purposes their combined concentrations will be presented as those of the 'triacylglycerol-rich lipoproteins' (TRL).

\section{Analytical methods}

TAG was measured in plasma and the lipoprotein fractions by an enzymic colorimetric method with correction for free glycerol (Humphreys et al. 1990). Total cholesterol and free cholesterol were measured by enzymic methods (Biotrol, Paris, France); cholesterol ester concentration was determined from the difference between total and free cholesterol concentrations (free and esterified cholesterol were only estimated in nine subjects). Apolipoproteins A1 and B were measured by immunoturbidimetric methods; anti-human apolipoprotein antisera and calibration serum were obtained from Boehringer Mannheim, Lewes, East Sussex, and the assay was controlled against Precinorm L Lipid Control Serum and Precilip EL Lipid Control Serum (Boehringer Mannheim). All the methods were adapted to an IL Monarch Clinical Chemistry Analyzer (Instrumentation Laboratory, Warrington, Ches.).

Insulin was measured using a double-antibody radioimmunoassay.

\section{Calculations and statistical analysis}

Results are shown as means with their standard errors. For statistical analyses the results from the three samples taken before eating were averaged to give a 'mean basal' value. The term 'mean peak' refers to the meaned values at $3-6 \mathrm{~h}$ after the meal for each individual. Differences between basal and postprandial values were assessed by the paired $t$ test. Correlations were analysed by the non-parametric Spearman's test, and Spearman correlation coefficients $\left(r_{s}\right)$ are quoted. 


\section{RESULTS}

$T A G$

The plasma fasting TAG concentrations varied widely (range $0.38-2.70 \mathrm{mmol} / \mathrm{l}$ ) between the subjects. The plasma TAG concentration increased significantly during the postprandial period (Table 1, Fig. 1) and no individual showed a biphasic curve. The individual peak TAG concentration also varied considerably between subjects (range 0.68-3.76 mmol/l) and the time of the individual peaks varied from 3-6h following the meal, with an average peak value at $5 \mathrm{~h}$ (Fig. 1).

The rise in plasma TAG was due largely to an increase in the TAG concentration in the TRL, with parallel and significant rises in the TAG concentration in the chylomicron and VLDL fractions (Fig. 1). These were accompanied by a smaller, although highly significant, increase in the HDL-TAG concentration (Fig. 1; Table 2). The peak chylomicron TAG concentration was observed at $4 \mathrm{~h}(276$ (SE 32) $\mu \mathrm{mol} / 1)$, whereas the VLDL-TAG concentration peaked slightly later at $5 \mathrm{~h}$ (1005 (SE 185) $\mu \mathrm{mol} / \mathrm{l})$.

The concentration of apo B in plasma decreased after the meal (Table 1), whereas it rose in the TRL (Table 2). The TAG: apo B ratio in the TRL (a measure of particle size) rose after the meal (Table 2).

\section{Cholesterol}

The fasting plasma cholesterol concentrations were $3.46 .4 \mathrm{mmol} / \mathrm{l}$. They did not change after the meal (Table 1). There were, however, significant postprandial changes in cholesterol concentrations in the lipoprotein fractions (Table 2). TRL-cholesterol increased following the meal while HDL-cholesterol decreased. LDL-cholesterol remained unchanged.

In those subjects in whom free and esterified cholesterol concentrations were analysed, there were no significant postprandial changes in plasma concentrations of either (Table 3). In the TRL the increase in total cholesterol was largely due to an increase in free cholesterol (Table 3). In contrast to the TRL, the postprandial decrease in HDL-cholesterol was due to a decrease in both free and esterified cholesterol concentrations (Table 3). In the LDL fraction there were no changes in free or esterified cholesterol concentrations (Table 3).

The postprandial changes in TAG and esterified cholesterol in the HDL fraction resulted in a change in composition of postprandial HDL core lipids (TAG: cholesteryl ester molar ratio, mean basal 0.185 (SE 0.042) vs. mean peak 0.227 (SE 0.051), $P<0.02$ ).

Plasma apo A1 concentrations decreased after the meal (Table 1).

\section{Correlations between fasting and postprandial lipoprotein concentrations}

The fasting plasma TAG concentration correlated positively with BMI $\left(r_{s} 0 \cdot 71, P<0 \cdot 001\right)$. Both TRL-apo $B$ and TRL-cholesterol concentrations were correlated with the fasting plasma TAG concentration $\left(r_{s} 0.78, P<0.001\right.$ and $r_{s} 0.91, P<0.001$ respectively). The HDL-cholesterol concentration was inversely correlated to the plasma TAG concentration in the fasting state $\left(r_{s}-0.63, P<0.01\right)$. Fasting plasma insulin concentrations were positively associated with fasting TAG concentrations $\left(r_{s} 0.66, P<0.01\right)$.

The peak TAG concentration (mean over 3-6 h) after the meal was strongly correlated with the fasting plasma TAG concentration $\left(r_{s} 0.91, P<0.001\right)$. The increase in plasma TAG concentration after the meal was quantified as the mean $3-6 \mathrm{~h}$ value minus the fasting value, and was also positively related to the fasting plasma TAG concentration $\left(r_{s} 0 \cdot 57\right.$, $P<0.01)$. Both were also related to the BMI $\left(r_{s} 0.73, P<0.001\right.$ and $r_{s} 0.61, P<0.01$ respectively).

The increase in TRL-cholesterol after eating was positively correlated with the increase 
Table 1. Plasma concentrations of triacylglycerol (TAG), cholesterol and apolipoproteins (apo) before and after a mixed meal in twenty subjects $\dagger$

(Mean values with their standard errors)

\begin{tabular}{|c|c|c|c|c|c|c|c|c|}
\hline & \multicolumn{2}{|c|}{ Mean basal } & \multicolumn{2}{|c|}{$60-120 \mathrm{~min}$} & \multicolumn{2}{|c|}{$180-240 \mathrm{~min}$} & \multicolumn{2}{|c|}{$300-360 \mathrm{~min}$} \\
\hline & Mean & $\mathrm{SE}$ & Mean & $\mathbf{S E}$ & Mean & SE & Mean & $\mathbf{S E}$ \\
\hline $\mathrm{TAG}(\mu \mathrm{mol} / \mathrm{l})$ & 1268 & 166 & $1388^{*}$ & 181 & $1857 * * *$ & 211 & $1860 * * *$ & 223 \\
\hline Cholesterol $(\mathrm{mmol} / \mathrm{l})$ & $4 \cdot 72$ & 0.24 & $4 \cdot 71$ & 0.23 & 4.67 & 0.22 & 4.69 & 0.22 \\
\hline Apo B (mg/l) & 593 & 49 & 584 & 48 & 577 & 47 & $579 *$ & 46 \\
\hline Apo Al $(\mathrm{mg} / \mathrm{l})$ & 1125 & 83 & 1098 & 77 & $1078^{*}$ & 78 & $1073^{* * *}$ & 83 \\
\hline
\end{tabular}

Mean value was significantly different from the mean basal concentration: $* P<0.05,{ }^{* *} P<0.01$, **** $P<0.001$.

$\dagger$ For details of subjects and procedures, see pp. 102-103.
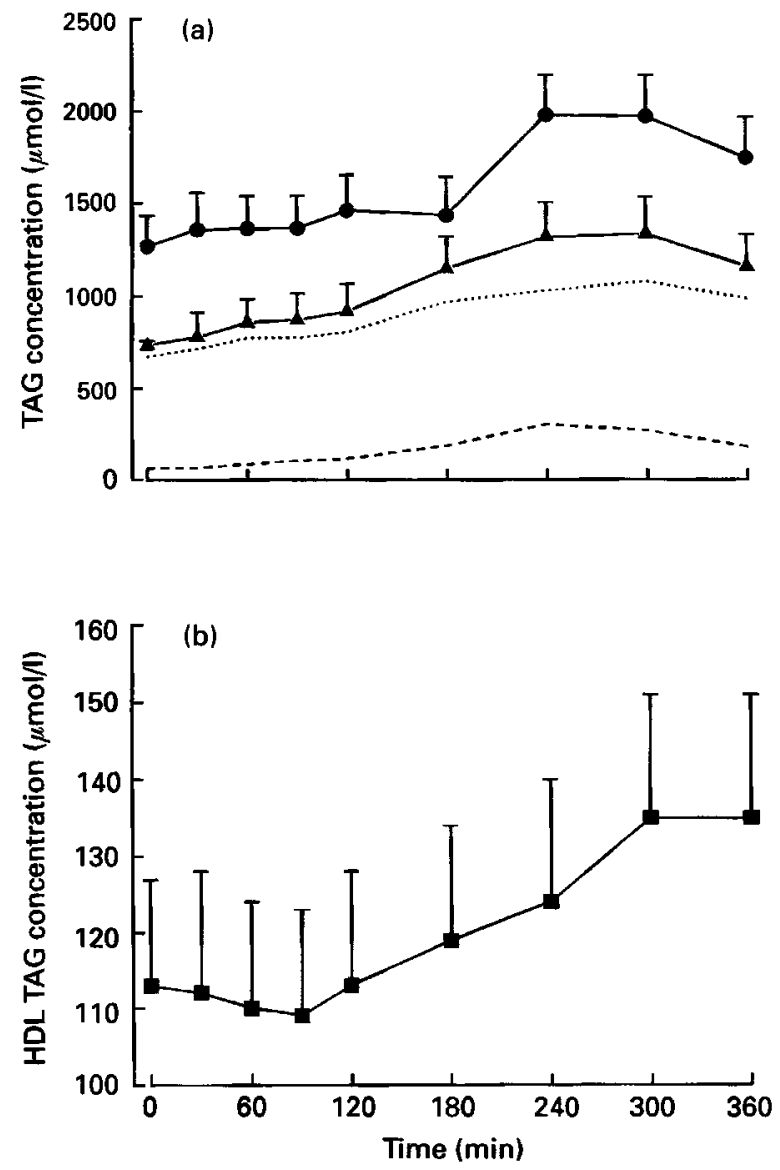

Fig. 1. Concentrations of triacylglycerol (TAG) in various plasma fractions before and after a mixed meal. Values are means with their standard errors represented by vertical bars. (a) TAG, concentrations in plasma (O) and TAG-rich lipoproteins (A) for twenty subjects; very-low-density-lipoprotein TAG (...) and chylomicron TAG $(---)$ concentrations are also shown. (b) High-density-lipoprotein (HDL) TAG concentrations ( subjects. 
Table 2. Fasting and postprandial (mean 3-6 h) triacylglycerol (TAG), cholesterol and apolipoprotein (apo) composition of lipoprotein fractions before and after a mixed meal* (Mean values with their standard errors for sixteen or twenty subjects)

\begin{tabular}{|c|c|c|c|c|c|}
\hline & \multicolumn{2}{|c|}{ Mean basal } & \multicolumn{2}{|c|}{ Mean peak $(3-6 h) \dagger$} & \multirow[b]{2}{*}{$P$ value } \\
\hline & Mean & $\mathrm{SE}$ & Mean & $\mathrm{SE}$ & \\
\hline TRL-TAG $(\mu \mathrm{mol} / \mathrm{l})$ & 802 & 157 & 1288 & 212 & $<0.001$ \\
\hline TRL-apo B (mg/l) & $39 \cdot 6$ & $4 \cdot 1$ & 53.5 & 46 & $<0.001$ \\
\hline TRL-TAG:apo B ratio $(\mu \mathrm{mol} / \mathrm{mg})$ & $20 \cdot 2$ & 2.9 & $24 \cdot 6$ & $3 \cdot 4$ & $<0.01$ \\
\hline LDL-TAG $(\mu \mathrm{mol} / \mathrm{l})$ & 261 & 26 & 259 & 24 & NS \\
\hline HDL-TAG $(\mu \mathrm{mol} / 1)$ & 120 & 14 & 130 & 16 & $<0.01$ \\
\hline TRL-cholesterol (mmol/l) & 0.41 & 0.07 & 0.58 & 0.09 & $<0.001$ \\
\hline LDL-cholesterol $(\mathrm{mmol} / \mathrm{l})$ & 2.49 & 0.23 & $2 \cdot 38$ & 0.2 & $<0.05$ \\
\hline HDL-cholesterol (mmol/l) & 1.00 & 0.08 & 0.95 & 0.06 & $<0.05$ \\
\hline
\end{tabular}

TRL, triacylglycerol-rich lipoproteins; LDL, low-density lipoprotein; HDL, high-density lipoprotein; NS, not significant.

* For details of subjects and procedures, see pp. 102-103.

$\dagger$ Mean peak values represent the mean concentration over the period from 3 to $6 \mathrm{~h}$ after the meal.

$\ddagger P$ values are given for the difference between basal and peak values.

Table 3. Plasma and lipoprotein free and esterified cholesterol concentration ( $m m o l / l)$ before and after a mixed meal*

(Mean values with their standard errors for nine subjects)

\begin{tabular}{|c|c|c|c|c|c|}
\hline & \multicolumn{2}{|c|}{ Mean basal } & \multicolumn{2}{|c|}{ Mean peak $(3-6 \mathrm{~h}) \dagger$} & \multirow[b]{2}{*}{$P$ value $f$} \\
\hline & Mean & SE & Mean & SE & \\
\hline Plasma free cholesterol & $1 \cdot 31$ & $0 \cdot 16$ & 1.36 & $0 \cdot 14$ & NS \\
\hline Plasma esterified cholesterol & $3 \cdot 41$ & 0.52 & $3 \cdot 44$ & 0.44 & NS \\
\hline TRL free cholesterol & 0.169 & 0.039 & 0.229 & $0 \cdot 044$ & $<0.05$ \\
\hline TRL esterified cholesterol & 0.225 & 0.048 & 0.324 & 0.047 & NS \\
\hline LDL free cholesterol & 0.83 & $0 \cdot 12$ & 0.76 & 0.09 & NS \\
\hline LDL esterified cholesterol & $2 \cdot 04$ & 0.41 & 1.96 & 0.37 & NS \\
\hline HDL free cholesterol & 0.31 & 0.06 & 0.25 & 0.04 & $<0.05$ \\
\hline HDL esterified cholesterol & 0.76 & 0.08 & 0.71 & 0.08 & $<0.05$ \\
\hline
\end{tabular}

TRL, triacylglycerol-rich lipoproteins; LDL, low-density lipoprotein; HDL, high-density lipoprotein; NS, not significant.

* For details of subjects and procedures, see pp. 102-103.

+ Mean peak values represent the mean concentration over the period from 3-6 $h$ after the meal.

$\ddagger P$ values are given for the difference between basal and peak values.

in TRL-TAG (Fig. 2(a)). The increase in HDL-TAG concentration after the meal, quantified as the mean $3-6 \mathrm{~h}$ value minus the fasting value, was positively related to both the postprandial (mean 3-6 h) plasma TAG concentration, and the increase in plasma TAG concentration after the meal $\left(r_{8} 0.53, P<0.05\right.$ and $r_{s} 0.57, P=0.02$ respectively) and also to the increase in TRL-TAG (Fig. 2(b)). 

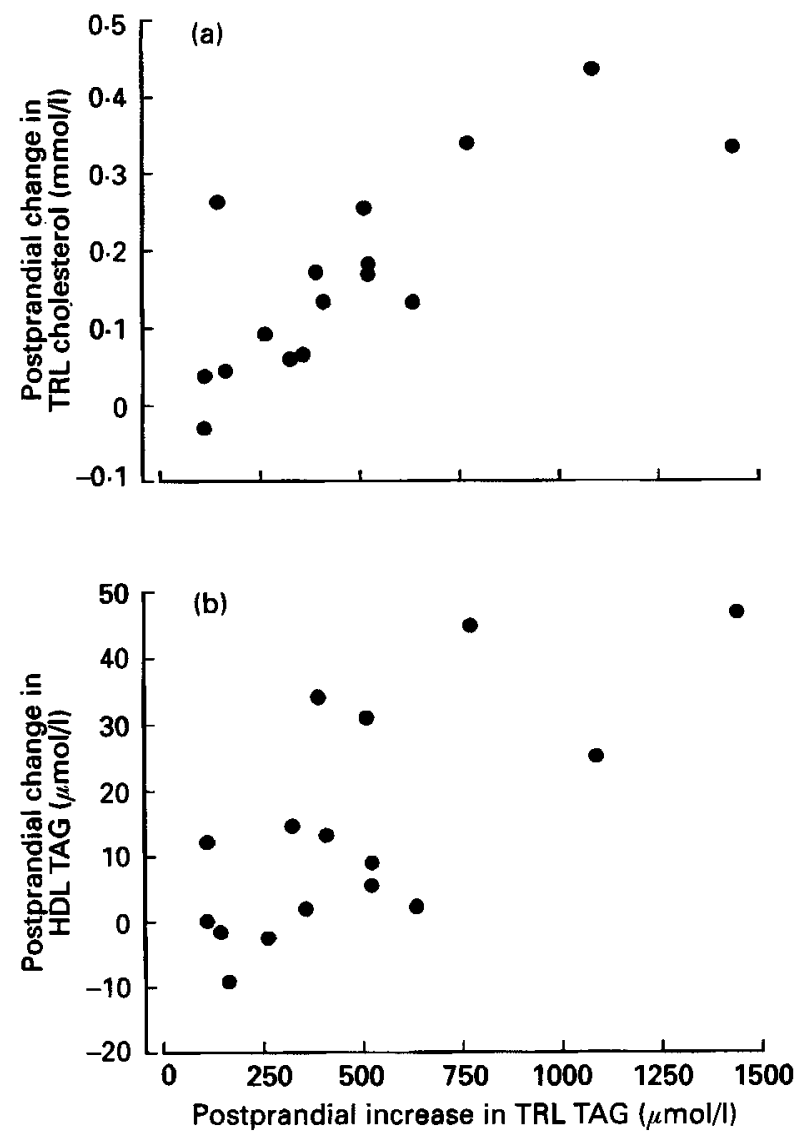

Fig. 2. Relationship between the postprandial increase in triacylglycerol-rich lipoprotein (TRL) triacylglycerol (TAG) concentration and (a) TRL cholesterol concentration $\left(r_{s} 0.78, P<0.001\right)$ and (b) high-density-lipoprotein (HDL) TAG concentration $(r, 0.71, P=0.002)$. The postprandial change is calculated as the mean concentration from 3-6 h after the meal minus the mean basal concentration.

\section{DISCUSSION}

Plasma TAG concentrations increased in all the subjects in response to the mixed meal. No biphasic peaks were observed as reported by some investigators (Cohn et al. 1988, 1989) who gave subjects a larger fat load. The postprandial increase in plasma TAG in these studies was due to significant increases in TAG in the TRL (chylomicron and VLDL) and HDL lipoprotein fractions. Since each TRL particle contains one molecule of apo B (Elovson et al. 1988) the TAG:apo B ratio gives a measure of particle size. The increase in TRL-TAG concentration was thus due to an increase in the size of particles more than an increase in the number of particles present.

The present findings confirm observations made after large fat loads (Patsch et al. 1983, 1984): enrichment of the TRL with TAG was accompanied by an increase in TAG, and a decrease in cholesterol (particularly esterified cholesterol), in the HDL fraction. Further, there was, as commonly observed, considerable variability in the postprandial TAG response, related primarily to the fasting TAG concentration (Cohn et al. 1988; O'Meara et al. 1992). In turn, the fasting TAG concentration in these studies, as in others (Lewis $e t$ al. 1990; Akanji et al. 1992), was related to the adiposity of the subjects. Those subjects with 
higher fasting levels of TAG showed the greatest response to the meal, and this was associated with greater enrichment of HDL with TAG, and also with greater enrichment of the TRL with cholesterol. In this respect, our design was different from most studies of large fat loads, in which the amount of fat administered has usually been related to body weight or surface area. We chose to feed all subjects the same meal; thus, the more obese subjects consumed less fat per unit body weight, but still displayed greater elevations in TAG concentration in the postprandial period.

The enrichment of HDL with TAG, and its depletion of cholesterol, in the postprandial period is considered to represent the action of the cholesteryl-ester transfer protein (CETP), exchanging HDL-cholesteryl ester mol for mol with TRL-TAG (Miesenböck \& Patsch, 1992). Within relatively normal ranges of plasma lipid concentrations, this process is governed by the lipid concentrations in the various lipoprotein fractions rather than by the activity of CETP in individual subjects (Mann et al. 1991). Thus, those with a greater or more prolonged postprandial elevation in TRL-TAG concentration have greater postprandial changes in the HDL fraction, and here we confirm that this is true even after a normal meal. The consequences of this lipid exchange are twofold. First, HDL-TAG may be removed by the action of hepatic lipase ( $E C 3.1 .1 .3)$, leading to smaller, lipid-depleted $\mathrm{HDL}$ particles of the $\mathrm{HDL}_{3}$ fraction rather than the larger, cholesteryl ester-rich $\mathrm{HDL}_{2}$ fraction which is associated with protection against coronary heart disease (Patsch et al. 1983; Miesenböck \& Patsch, 1992). Secondly, enrichment of the TRL remnants with cholesterol may lead to an increase in their atherogenic potential (Zilversmit, 1979; Chen \& Reaven, 1991).

In summary, our results show that the consumption of a relatively normal mixed meal is associated with similar changes in the composition of plasma lipoprotein fractions to those observed after larger fat loads. The results confirm that those subjects with elevated fasting TAG concentration are predisposed to changes in the postprandial period which may have adverse consequences in terms of risk of CHD. The cumulative effect of such changes, occurring in response to meals on a daily basis over many years, may aggravate the process of atherosclerosis in those at risk. Our results give firm support to the idea that nutritional advice to subjects predisposed to these changes by virtue of an elevated fasting plasma TAG concentration should include advice to lower the fat content of the diet, thus minimizing postprandial changes in lipoprotein metabolism.

We thank Mo Clark for assistance with these studies. J.L.P. held a Glaxo Group Research Studentship. Financial support was provided by the British Heart Foundation and a Medical Research Council (MRC) project grant to the Metabolic Research Laboratory. The Oxford Lipid Metabolism Group is supported by the Oxford Diabetes Trust. G.F.G. is a member of MRC External Scientific Staff of the MRC at the University of Oxford.

\section{REFEREN CES}

Akanji, A., Nzegwu, A. \& Agbedana, E. (1992). Some determinants of postprandial lipaemia in Nigerian diabetic and non-diabetic subjects. British Journal of Nutrition 68, 153-162.

Chen, Y.-D. I. \& Reaven, G. M. (1991). Intestinally-derived lipoproteins: metabolism and clinical significance. Diabetes Metabolism Reviews 7, 191-208.

Cohn, J. S., McNamara, J. R., Cohn, S. D., Ordovas, J. M. \& Schaefer, E. J. (1988). Postprandial plasma lipoprotein changes in human subjects of different ages. Journal of Lipid Research 29, 469-479.

Cohn, J. S., McNamara, J. R., Krasinski, S. D., Russell, R. M. \& Schaefer, E. J. (1989). Role of triglyceride-rich lipoproteins from the liver and intestine in the etiology of postprandial peaks in plasma triglyceride concentration. Metabolism 38, 484490.

Coppack, S. W., Evans, R. D., Fisher, R. M., Frayn, K. N., Gibbons, G. F., Humphreys, S. M., Kirk, M. J., Potts, J. L. \& Hockaday, T. D. R. (1992). Adipose tissue metabolism in obesity: lipase action in vivo before and after a mixed meal. Metabolism 41, $264-272$. 
Coppack, S. W., Fisher, R. M., Gibbons, G. F., Humphreys, S. M., McDonough, M. J., Potts, J. L. \& Frayn, K. N. (1990). Postprandial substrate deposition in human forearm and adipose tissues in vivo. Clinical Science 79, 339-348.

Elovson, J., Chatterton, J. E., Bell, G. T., Schumaker, V. N., Reuben, M. A., Puppione, D. L., Reeve, J. R. Jr. \& Young, N. L. (1988). Plasma very low density lipoproteins contain a single molecule of apolipoprotein B. Journal of Lipid Research 29, 1461-1473.

Groot, P. H. E. \& Scheek, L. M. (1984). Effects of fat ingestion on high density lipoprotein profiles in human sera. Journal of Lipid Research 25, 684-692.

Havel, R. J., Eder, H. A. \& Bragdon, J. H. (1955). The distribution and chemical composition of ultracentrifugally separated lipoproteins in human serum. Journal of Clinical Investigation 34, 1345-1353.

Havel, R. J., Kane, J. P. \& Kashyap, M. L. (1973). Interchange of apolipoproteins between chylomicrons and high density lipoproteins during alimentary lipemia in man. Journal of Clinical Investigation 52, 32-38.

Humphreys, S. M., Fisher, R. M. \& Frayn, K. N. (1990). Micro-method for measurement of sub-nanomole amounts of triacylglycerol. Annals of Clinical Biochemistry 27, 597-598.

Karpe, F., Steiner, G., Olivecrona, T., Carlson, L. A. \& Hamsten, A. (1993). Metabolism of triglyceride-rich lipoproteins during alimentary lipemia. Journal of Clinical Investigation 91, 748-758.

Lewis, G. F., O'Meara, N. M., Soltys, P. A., Blackman, J. D., Iverius, P. H., Druetzler, A. F., Getz, G. S. \& Polonsky, K. S. (1990) Postprandial lipoprotein metabolism in normal and obese subjects: comparison after the vitamin A fat-loading test. Journal of Clinical Endocrinology and Metabolism 71, 1041-1050.

Lewis, G. F., O'Meara, N. M., Soltys, P. A., Blackman, J. D., Iverius, P. H., Pugh, W. L., Getz, G. S. \& Polonsky, K. S. (1991). Fasting hypertriglyceridemia in noninsulin-dependent diabetes mellitus is an important predictor of postprandial lipid and lipoprotein abnormalities. Journal of Clinical Endocrinology and Metabolism 72, $934-944$.

Mann, C. J., Yen, F. T., Grant, A. M. \& Bihain, B. E. (1991). Mechanism of plasma cholesteryl ester transfer in hypertriglyceridemia. Journal of Clinical Investigation 88, 2059-2066.

Miesenböck, G. \& Patsch, J. R. (1992) Postprandial hyperlipidemia: the search for the atherogenic lipoprotein. Current Opinion in Lipidology 3, 196-201.

O'Meara, N. M., Lewis, G. F., Cabana, V. G., Iverius, P. H., Getz, G. S. \& Polonsky, K. S. (1992). Role of basal triglyceride and high density lipoprotein in determination of postprandial lipid and lipoprotein responses. Journal of Clinical Endocrinology and Metabolism 75, 465-471.

Patsch, J. R., Karlin, J. B., Scott, L. W., Smith, L. C. \& Gotto, A. M. Jr. (1983). Inverse relationship between blood levels of high density lipoprotein subfraction 2 and magnitude of postprandial lipemia. Proceedings of the National Academy of Sciences 80, 1449-1453.

Patsch, J. R., Prasad, S., Gotto, A. M. Jr. \& Bengtsson-Olivecrona, G. (1984). Postprandial lipemia. A key for the conversion of high density lipoprotein into high density lipoprotein $_{3}$ by hepatic lipase. Journal of Clinical Investigation 74, 2017-2023.

Potts, J. L., Fisher, R. M., Humphreys, S. M., Coppack, S. W., Gibbons, G. F. \& Frayn, K. N. (1991). Peripheral triacylglycerol extraction in the fasting and post-prandial states. Clinical Science 81, 621-626.

Redgrave, T. G. \& Carlson, L. A. (1979). Changes in plasma very low density and low density lipoprotein content, composition, and size after a fatty meal in normo- and hypertriglyceridemic man. Journal of Lipid Research $\mathbf{2 0}$, $217-229$.

Simpson, H. S., Williamson, C. M., Olivecrona, T., Pringle, S., Maclean, J., Lorimer, A. R., Bonnefous, F., Bogaievsky, Y., Packard, C. J. \& Shepherd, J. (1990). Postprandial lipemia, fenofibrate and coronary artery disease. Atherosclerosis 85, 193-202.

Tall, A. R., Blum, C. B., Forester, G. P. \& Nelson, C. A. (1982) Changes in the distribution and composition of plasma high density lipoproteins after ingestion of fat. Journal of Biological Chemistry 257, 198-207.

Zilversmit, D. B. (1979). Atherogenesis: a postprandial phenomenon. Circulation 60, 473-485. 